\title{
Redefiniendo una categoría arquitectónica inca: la kallanka
}

Une catégorie architecturale inca à redéfinir : la kallanka

Redefining an Inca architectural category: kallanka

\section{Sergio Barraza Lescano}

\section{CpenEdition}

\section{Journals}

Edición electrónica

URL: http://journals.openedition.org/bifea/2129

DOI: $10.4000 /$ bifea.2129

ISSN: 2076-5827

\section{Editor}

Institut Français d'Études Andines

Edición impresa

Fecha de publicación: 1 abril 2010

Paginación: 167-181

ISSN: 0303-7495

\section{Referencia electrónica}

Sergio Barraza Lescano, « Redefiniendo una categoría arquitectónica inca: la kallanka », Bulletin de I'Institut français d'études andines [En línea], 39 (1) | 2010, Publicado el 01 octubre 2010, consultado el 06 noviembre 2020. URL : http://journals.openedition.org/bifea/2129 ; DOI : https://doi.org/10.4000/ bifea. 2129

\section{(2) $(\mathcal{Q} \Theta \Theta$}

Les contenus du Bulletin de l'Institut français d'études andines sont mis à disposition selon les termes de la licence Creative Commons Attribution - Pas d'Utilisation Commerciale - Pas de Modification 4.0 International. 


\title{
Redefiniendo una categoría arquitectónica inca: la kallanka
}

\author{
Sergio Barraza Lescano*
}

\begin{abstract}
Resumen
El uso de términos quechuas para definir formal y funcionalmente la cultura material incaica constituye una práctica muy generalizada entre los arqueólogos andinistas. En muy pocos casos, sin embargo, la elección de estos nombres se ve respaldada por un análisis histórico o lingüístico que justifique su empleo. En el presente artículo, centraremos nuestra atención en el estudio de una categoría arquitectónica ampliamente utilizada para referirse a las alargadas salas techadas existentes en los principales asentamientos incaicos: las kallankas. A partir de la revisión de información registrada en fuentes etnohistóricas, se propone su redefinición.
\end{abstract}

Palabras clave: kallanka, galpón, arquitectura inca

\section{Une catégorie architecturale inca à redéfinir : la kallanka}

\section{Résumé}

Les archéologues andinistes utilisent couramment des termes en langue quechua afin de traduire les aspects formels et fonctionnels de la culture matérielle des Incas. Rarement, cependant, le choix de ces vocables repose sur une analyse historique ou linguistique qui justifie son emploi. Cet article souhaite attirer l'attention sur une catégorie architecturale largement utilisée pour désigner les longs bâtiments que l'on trouve sur les principaux sites incas: les kallankas. Grâce aux informations fournies par les sources etnohistoriques, une redéfinition de cette catégorie sera proposée.

Mots clés : kallanka, hangar, architecture inca

* Instituto Riva-Agüero. Programa de Estudios Andinos PUCP. E-mail: barraza.sa@pucp.edu.pe 


\section{Redefining an Inca architectural category: kallanka}

\section{Abstract}

The use of quechua terms to define formally and functionally Inca material culture constitutes a generalized practice among Andean archaeologists. In very few cases, however, do the election of these terms rest on historical or linguistic analysis that justify their employment In this article, we will focus our attention on the study of an architectural category widely used to refer to large roofed halls existing in the principal Inca establishments: kallanka. After the review of ethnohistorical information, a redefinition of this category is proposed.

Key words: kallanka, galpón, Inca architecture

\section{INTRODUCCIÓN}

Desde mediados del siglo XIX, los estudios sobre la sociedad Inca se han caracterizado por la aplicación de un enfoque interdisciplinario favorecido por el fluido diálogo entre arqueólogos, historiadores, antropólogos y lingüistas. Los grandes logros conseguidos a través del empleo de este enfoque, sin embargo, también se han visto acompañados por algunos desaciertos metodológicos como el uso indiscriminado de términos quechuas para definir formal y funcionalmente la cultura material incaica.

Esta última práctica, si bien a primera vista puede parecer irrelevante, es particularmente importante dado que el empleo reiterado de estas voces quechua, tomadas acríticamente de los registros etnohistórico y etnográfico, les otorga la calidad de categorías clasificatorias portadoras de considerable carga semántica, convirtiéndolas así en «etiquetas» con implicancias morfofuncionales. En el caso específico de la arquitectura, es frecuente encontrar en las publicaciones arqueológicas el uso de términos como acllahuasi, colca, chulpa, kancha, kallanka, pucara, tambo y ushnu, y en menor proporción, chaucalla, huayrona y masma, para referirse a determinados tipos de estructuras y a las actividades a las que estuvieron asociadas. Sin embargo, en muy pocos casos, la elección de estos nombres es respaldada por un estudio histórico o lingüístico que justifique su empleo; la práctica más común (y más simplista) es la de repetir mecánicamente lo que otros investigadores escribieron previamente.

El presente artículo aborda el análisis de la denominada kallanka, una categoría arquitectónica que, si bien ha merecido ya la atención de algunos investigadores (Meinken, 2000-2001; 2005a; Muñoz, 2007), aún no ha sido cabalmente definida. A partir de la revisión de información registrada en fuentes etnohistóricas coloniales proponemos una redefinición de la misma.

\section{LAS KALLANKAS}

En las últimas décadas, se ha generalizado entre los arqueólogos andinistas el uso del término quechua kallanka para referirse a las estructuras alargadas incaicas que los cronistas de los siglos XVI y XVII Ilamaron galpones o salas; la gran difusión que ha tenido esta voz la ha convertido en una categoría tipológica imprescindible para caracterizar la arquitectura Inca. Sin embargo, iqué significaba originalmente esta palabra?, ¿cuándo y quién la introdujo en el círculo arqueológico? Son interrogantes aún sin respuesta. Resulta oportuno, entonces, tratar de precisar la acepción original del término kallanka y establecer si ha sido correctamente aplicado al interior del ámbito académico.

A continuación presentamos dos definiciones tomadas de los trabajos de Graziano Gasparini \& Luise Margolies (1977) y Craig Morris (1999) que resumen, en gran medida, las ideas que los arqueólogos manejamos sobre lo que es una kallanka.

«Un tipo de edificio que se encuentra en Cusco y se repite desde Cajamarca hasta Inkallaqta en Bolivia, es el Ilamado Kallanka... Las características generales de ese edificio son similares en todos los ejemplos conocidos y sólo varían las dimensiones. Se trata de un gran galpón de planta rectangular muy alargada con techos de dos aguas sostenido por series de pilares hincados a lo largo del eje longitudinal. Uno de los lados más largos, con varios vanos de entrada, da siempre sobre la plaza principal» (Gasparini \& Margolies, 1977: 204).

"Una forma arquitectónica que lleva el "sello" incaico, es un edificio rectangular, no dividido e inusitadamente largo, que las fuentes españolas tempranas llaman como galpones y al cual arquitectos y arqueólogos generalmente se refieren con el nombre de kallanka. Estos edificios tienen múltiples puertas en un lado y en muchos casos, múltiples ventanas y nichos en ambos lados. Raramente una puerta puede ser ubicada al final de la estructura» (Morris, 1999: 22).

A partir de las descripciones publicadas, es posible reconocer que las principales características arquitectónicas presentes en las denominadas kallankas son las siguientes:

- Planta rectangular alargada.

- Techo a dos aguas.

- Interior usualmente sin divisiones (espacio continuo).

- Presencia de postes o columnas internas para sostener el techado (en caso de tratarse de estructuras de grandes dimensiones).

- Presencia de hastiales.

- Varias puertas colocadas a intervalos en una de las paredes largas que da a la plaza.

La homogeneidad formal que parece reflejar esta categoría arquitectónica resulta, sin embargo, aparente, ya que se han identificado como kallankas estructuras 
rectangulares de muy variadas dimensiones, en un rango que va desde los 17 hasta los $105 \mathrm{~m}$ de largo' (cuadro 1).

\section{INTRODUCCIÓN DE LA CATEGORÍA KALLANKA EN LOS ESTUDIOS \\ ARQUEOLÓGICOS ANDINOS}

Pese al consensuado uso que actualmente se da al término kallanka en el argot arqueológico andinista, éste fue introducido por primera vez con una connotación muy distinta a la que manejamos hoy en día: Kkallancca, «sitio donde se guardan objetos circulares» (Pardo, 1957: 52). La reintroducción de este nombre para referirse a las estructuras incaicas alargadas o galpones fue obra de Craig Morris y del personal del Institute of Andean Research dirigido por John V. Murra, quienes lo emplearon para describir este tipo de construcciones en el marco de sus estudios en Huanuco Pampa iniciados en 1963. En una de las primeras publicaciones de este proyecto, Morris escribiría:

«Inmediatamente al este de la estructura D (del Tampu Real de Tunsucancha) se encuentra la plaza mayor de Tunsucancha, formada por tres edificios longitudinales conocidos como kallanka. Forman los lados sur, este y oeste de la plaza» (Morris, 1966: 103)

Si bien Craig Morris nunca precisó la fuente de la cual tomó el término quechua kallanka, es muy probable que lo hubiera recogido del registro etnográfico. Al respecto, es oportuno citar las siguientes palabras de Ramiro Matos (1994: 214):

«... es interesante mencionar que recién después de las investigaciones llevadas a cabo en Huánuco, por el equipo de arqueólogos que dirigió John V. Murra entre 1963 y 1966, términos como usnu, kallanka, kancha, colca, etc. ingresaron o reingresaron al lenguaje moderno del poblador de la región, designando con esos nombres, estructuras similares a las que se hallaron en aquella localidad. La promoción de esta nomenclatura recuperada o creada, se debe principalmente a los profesores de colegios [...]. Con el nombre de kallanka fueron bautizados los salones más grandes en los asentamientos Inka. No sabemos con precisión de cuándo data; pues no aparece en el vocabulario quechua de González Holguín. De cualquier forma, juzgamos que esta designación es mejor que las otras igualmente modernas, como galpones o barracas. Las kallankas fueron de planta rectangular, sin divisiones internas» (Matos, 1994: 214, 222).

Como lo señala Matos, la nueva nomenclatura ha trascendido el ámbito académico introduciéndose en algunos diccionarios regionales, como en el de la Academia Mayor de la Lengua Quechua del Cuzco, donde aparece registrado el término kallanka con la siguiente acepción:

1 María de los Ángeles Muñoz (2007: 257) ha optado por definir la categoría arquitectónica kallanka a partir de la gran dimensión de las estructuras (un mínimo de $40 \mathrm{~m}$ de largo) y de su emplazamiento dentro del complejo arquitectónico mayor (con las ventanas o puertas de cara a una plaza).
Cuadro 1 - Dimensiones de algunos galpones incaicos

\begin{tabular}{|l|c|c|l|}
\hline \multicolumn{1}{|c|}{ Nombre del sitio } & Largo en $\mathbf{m}$ & Ancho en $\mathbf{m}$ & \multicolumn{1}{|c|}{ Fuente } \\
\hline Pumpu (Junín) & 105 & 9,5 & Matos, 1994: 223 \\
\hline Templo de Raqchi & 92 & 25,25 & Sillar \& Dean, 2002: 233 \\
\hline Inkallajta (Bolivia) & 78 & 26 & Muñoz, 2007: 257 \\
\hline Samaipata (Bolivia) & 68 & 16 & Muñoz, 2007: 256 \\
\hline Huánuco Pampa & 65 & 12 & Morris \& Thompson, 1985: 89 \\
\hline Ccopan (Arequipa) & 51,5 & 10 & Meinken, 2005b: 65 \\
\hline Machupitumarca (Cusco) & 49,6 & 9,2 & Samanez \& Zapata, 2001: 95 \\
\hline El Shincal (Argentina) & 47 & 11 & Raffino et al., 2000: 343 \\
\hline Pumpu (Junín) & 45 & 6,5 & Matos, 1994: 169 \\
\hline Huchuy Cusco (Cusco) & 40 & 12 & Bouchard, 1983: 95 \\
\hline Achaymarca (Arequipa) & 39,3 & 10,6 & Meinken, 2000-2001: 140 \\
\hline El Shincal (Argentina) & 33,3 & 5,6 & Raffino et al., 2000: 317 \\
\hline Choquequirao (Apurímac) & 33 & 7,5 & Samanéz \& Zapata, 1999: 93 \\
\hline Tompullo 2 (Arequipa) & 31,03 & 6,30 & Meinken, 2000-2001: 137 \\
\hline Tambokancha (Cusco) & 31 & 7 & Farrington \& Zapata, 2003: 68 \\
\hline La Joya (Arequipa) & 30,9 & 11,25 & Meinken, 2005b: 81 \\
\hline Tambokancha (Cusco) & 29,8 & 14,2 & Farrington \& Zapata, 2003: 67 \\
\hline Maucallacta (Arequipa) & 28 & 8 & Meinken, 2000-2001: 143 \\
\hline Sondor (Apurímac) & 27 & 10 & Pérez et al., 2003: 371 \\
\hline Ccopan (Arequipa) & 26,1 & 9,05 & Meinken, 2005b: 71 \\
\hline Ccopan (Arequipa) & 25,9 & 11,35 & Meinken, 2005b: 65 \\
\hline La Joya (Arequipa) & 25,63 & 9,54 & Meinken, 2005b: 82 \\
\hline Maucallacta (Arequipa) & 24 & 9 & Meinken, 2000-2001: 131 \\
\hline Maucallacta (Arequipa) & 23 & 10 & Meinken, 2005a: 59 \\
\hline Ccopan (Arequipa) & 21,8 & 11,41 & Meinken, 2005b: 73 \\
\hline Huamanmarca (Arequipa) & 21 & 6 & Meinken, 2005a: 60 \\
\hline Ccopan (Arequipa) & 21,1 & 9,84 & Meinken, 2005b: 71 \\
\hline Ccopan (Arequipa) & 20,48 & 8,88 & Meinken, 2005b: 71 \\
\hline Maucallacta (Arequipa) & 20 & 9 & Meinken, 2000-2001: 127 \\
\hline Incarracay (Bolivia) & 20 & 6 & Caballero, 1980: 4 \\
\hline Ccopan (Arequipa) & 19,4 & 9,3 & Meinken, 2005b: 73 \\
\hline Sondor (Apurímac) & 19 & 7 & Pérez et al., 2003: 368 \\
\hline Sondor (Apurímac) & 17 & 8 & Pérez et al., 2003: 371 \\
\hline
\end{tabular}


«Edificio techado de grandes proporciones que servía para alojar masas humanas en las celebraciones de la época inkaica» (1995: 195).

\section{FUNCIONALIDAD ATRIBUIDA A LAS DENOMINADAS KALLANKAS}

Los cronistas coloniales y los investigadores modernos que han estudiado la arquitectura incaica han atribuido a los galpones incaicos las más diversas funcionalidades:

- Palacios de los soberanos incas o alojamientos para individuos importantes (Calancha, 1974-1981 [1638]: 537; Muñoz, 2007: 256; Vega, 1948 [1600]: 11).

- Cuarteles o barracas para los soldados del Inca (Hyslop, 1990: 18; Meinken, 2005a: 62; Morris, 1966: 103; Muñoz, 2007: 263-264).

- Plazas techadas «para sus fiestas y bailes» cuando las condiciones climáticas externas no permitían reunirse al aire libre (Garcilaso, 2005 [1609]: 335; Muñoz, 2007: 256).

- Talleres y/o alojamientos para los tributarios del sistema de mita (Hyslop, 1990: 18; Meinken, 2005a: 62; Zecenarro, 2000: 92)

- Alojamientos colectivos temporales para transeúntes (Agurto, 1987: 49, Morris, 1972: 140), por ejemplo peregrinos rumbo a santuarios (Meinken, 2005a: 62).

- Lugares de reunión pública o asamblea (Matos, 1994: 134; Morris, 1966: 103).

- Templos (Muñoz, 2007: 256; Polo de Ondegardo, 1916 [1571]: 96).

- Uso colectivo, propósitos múltiples (Malpass, 1993: 9), «debió adaptarse a situaciones y finalidades diferentes» (Gasparini \& Margolies, 1977: 208).

\section{HALLAZGOS ARQUEOLÓGICOS REALIZADOS AL INTERIOR DE} LAS KALLANKAS

La escasa información publicada referente a los hallazgos efectuados al interior de las denominadas kallankas, permite reconocer que los tiestos y restos faunísticos son los materiales más recurrentemente reportados. Si bien esta situación podría inducirnos a prefigurar un carácter doméstico o habitacional para este tipo de estructuras, no podemos descartar la posibilidad de que tuvieran una naturaleza multifuncional dado que, esporádicamente, se han encontrado asociadas al descubrimiento de armas (proyectiles de boleadora) y restos humanos.

- Kallanka de Maucallacta (Arequipa): tiestos, carbón vegetal y restos óseos de llama (Meinken, 2000-2001: 135).

- Kallanka de Pukara de Turi (Chile): restos óseos de llama, algunos con huellas de corte (Becker, 1995).
Redefiniendo una categoría arquitectónica Inca: la kallanka

- Kallanka de Ccopan (Arequipa): tiestos y material óseos (Meinken, 2005b: $69,74)$

- Kallanka de La Joya (Arequipa): contexto funerario de 2 infantes (fardo) con asociaciones constituidas por 1 botella Inca tipo florero o tticachurana decorada, 1 cántaro, 1 olla con pedestal Inca, 2 alfileres o tupus, 2 vasos de madera (keros), 2 vasijas de estilo local (Chuquibamba) y ovillos de lana (Meinken, 2005b: 83-88).

- Kallanka de Huánuco Pampa (Huánuco): tiestos que no presentaban indicadores de uso de la estructura (Morris \& Thompson, 1985: 89).

- Kallanka de Samaipata (Bolivia): tiestos, pulidores de piedra y proyectiles líticos de boleadora (Muñoz, 2007: 263)

\section{SIGNIFICADO DEL TÉRMINO KALLANKA EN EL REGISTRO LINGÜÍSTICO Y ETNOHISTÓRICO}

A pesar de la gran difusión que ha tenido el nombre kallanka para referirse a los galpones incaicos, no han faltado justificados cuestionamientos sobre su uso a nivel científico. Al respecto podemos mencionar las observaciones expuestas por John Rowe (citado por Protzen) y John Hyslop:

«En la literatura... estas salas grandes son usualmente referidas como kallanka. Rowe me indicó que los Incas del Cuzco no habrían utilizado este término para describir la forma o tamaño de una construcción» (Protzen, 1993: 70, nota 3; traducción propia).

«La palabra kallanka utilizada para definir una forma de construcción es de origen reciente. Un término más apropiado podría ser buscado. Los primeros españoles en los Andes llamaron a estas salas galpones» (Hyslop, 1990: 19; traducción propia).

Frente a estas observaciones, hemos considerado oportuno revisar la connotación que el término kallanka ha recibido en el registro lingüístico y etnohistórico desde tiempos coloniales. En los diccionarios quechuas modernos, la palabra kallanka es interpretada como «piedra de sillería» (Carranza, 2003: 91), mientras que sus derivados kallankarumi y kallankawasi son traducidos como «piedra labrada para construcción» y «casa de piedra labrada» respectivamente (Lara, 1978: 100). No obstante, resulta obvio que estas definiciones provienen del vocabulario quechua de Diego González Holguín impreso en 1608, en donde callancarumi y callancahuaci son interpretados, respectivamente, como «piedras grandes labradas, de sillería para cimientos y umbrales» y «casa fundada sobre ellas (callancarumi)» (González Holguín, 1989 [1608]: 44).

Las definiciones presentadas por el lenguaraz jesuita no ofrecen ninguna información que permita asociar el término quechua con una forma arquitectónica particular, por ejemplo, los galpones incaicos. Existe sin embargo, otra fuente lingüística colonial, ya no del quechua sino del aimara, que brinda informaciones sobre el uso de la palabra callanca para referirse a los corrales; nos referimos al Arte de la Lengua Aymara de Ludovico Bertonio, en donde se registra «Callanca, vel Cachi. Corral» (Bertonio, 1984 [1612]: 33) 
La aparición del término en el Arte de Bertonio y como topónimo en la región de Chucuito (Puno), territorio con población aimara hablante, ha llevado a la arqueóloga alemana Anja Kathrin Meinken (2005a: 57) a plantear el origen aimara de esta categoría arquitectónica²; como veremos a continuación, algunos registros etnohistóricos respaldan esta posibilidad.

Si bien es poco frecuente encontrar el uso de la palabra kallanka en las fuentes documentales de los siglos XVI y XVII, su presencia en algunas de ellas remite a la definición aimara de Bertonio, permitiendo reconocer que esta voz no se encuentra vinculada a ningún tipo de espacio arquitectónico cerrado, sino, muy por el contrario, a espacios abiertos comparables a las kanchas (patios o corrales). Asimismo, la información extraída de estas mismas fuentes sugiere que se trataba de áreas destinadas a actividades ceremoniales.

Una de las referencias más claras proviene del llamado «Manuscrito de Huarochirí», redactado a inicios del siglo XVII; de este texto hemos tomado el siguiente párrafo:

«Mantuvo su palabra (Pariacaca) y en la fiesta de Chaupiñamca apareció

un gato montés todo él muy hermosamente pintado, sobre la pared de su cancha llamada Yauricallanca» (Taylor, 1999 [1608]: 313).

En este caso, la voz callanca se encuentra asociada al patio (kancha) dedicado a la diosa huarochirana Chaupiñamca.

En los documentos producidos durante las campañas de extirpación de idolatrías desarrolladas en el Arzobispado de Lima, en el siglo XVII, se menciona frecuentemente unas ofrendas de concha Spondylus molida que recibían el nombre de coricallancas; éstas solían ser colocadas en «vn corralito sercado de piedras» (Duviols, 2003: 456) que muy probablemente correspondía a una callanca similar a la mencionada en Huarochirí.

En esta misma documentación, también podemos encontrar algunos topónimos que, indudablemente, remiten a estas estructuras ceremoniales. En el pueblo cajatambino de San Pedro de Acas, por ejemplo, un acusado de hechicería señala en 1657:

«Y asi mesmo que este testigo adora al sol con los de su aillo ofresiendole mais blanco molido y plumas de los guachuas que son vnos pagaros de la puna a manera de gansos y esta ofrenda hasian en el sitio Callanca y alli esta vna cancha pequeña donde ponen las ofrendas...» (Duviols, 2003: 351).

2 Meinken ha señalado al respecto: «... queda la interrogante, si la palabra kallanka verdaderamente es de origen quechua... En la región de Chucuito, cerca de la ciudad de Puno, Perú, una región mayormente habitada por aimara-hablantes, existe un lote que lleva el nombre "kallanka". En el idioma aimara, por ejemplo, en el diccionario de Ludovico Bertonio (1612) los verbos compuestos de calla- llevan el significado de plantar, o de actividades relacionadas a animales (como callacata: poner bien). Ello indica, que un lote llamado kallanka podría ser interpretado como un tipo de corral. Lamentablemente, la consulta de diccionarios aimaras tampoco genera evidencia de la palabra kallanka como término arquitectónico, pero permite llegar a la conclusión, que la palabra misma posiblemente es de origen aimara y que luego habría sido adaptada al idioma quechua» (2005a: 57)
El carácter ceremonial de este tipo de estructuras se ve confirmado en uno de los párrafos de la Relación de ceques del Cuzco copiada por el jesuita Bernabé Cobo; a referirse a la sexta huaca del séptimo ceque del Chinchaysuyu, el cronista escribió:

«La sesta (guaca) se decía, callancapuquiu, es el manatial de Ticutica [sic Ticatica], al qual ofrecian conchas porque siempre manase» (Rowe, 1981 : 228)

Como se puede apreciar, nuevamente está presente la asociación entre el término callanca y las ofrendas de concha (probablemente Spondylus).

Las referencias etnohistóricas presentadas, si bien son escasas, permiten conceptualizar la callanca incaica como un espacio arquitectónico abierto con clara función ceremonial, muy distante de las salas o galpones a los que, no siempre, se les ha adjudicado este nombre quechua. ¿Cuál era, entonces, el nombre indígena que recibían estos últimos? Para poder responder a esta pregunta, resulta necesario focalizar nuestra atención en el carácter palaciego atribuido por algunos cronistas a los galpones del Tahuantinsuyu y en la denominación que recibieron por parte de los incas.

\section{CARACTER PALACIEGO DE LOS GALPONES INCAICOS EN LAS FUENTES ETNOHISTÓRICAS DEL SIGLO XVII}

Como ya ha sido señalado, algunos cronistas del siglo XVII atribuyeron a los galpones incaicos una función palaciega o de «casas reales». El agustino Antonio de la Calancha, por ejemplo, al hacer una precisión etimológica del nombre Rimac Tanpu señala:

«quiere decir, casa, vivienda, o mesón del Dios que abla; aunque lo que se

llamava Tanpu, era casa Real que cada pueblo tenía en que se aposentase

el Inga; i era un Galpón» (Calancha 1974-1981 [1638]: 537).

En forma similar, en su «Historia del Colegio y Universidad de San Ignacio de Loyola de la Ciudad del Cuzco» (1600), el jesuita Antonio de Vega vincula los palacios de los Incas y los galpones al aclarar que la estructura incaica ocupada por la Compañía de Jesús en la ciudad imperial, Amarocancha (casa de sierpes), debía su nombre a que:

«en unas salas o palacios (que acá llamamos galpones) tenían los incas muy

al vivo labradas unas grandes sierpes, o culebras de piedra...» (Vega, 1948 [1600]: 11).

Finalmente, la asociación palacio inca-galpón vuelve a estar presente en el dibujo de los «palacios del Ynga y de la Coya» reproducido en la crónica del mercedario fray Martín de Murúa (2004 [1590]: fol. 65v), en donde podemos apreciar la representación de dos estructuras alargadas construidas con piedra sillar («casas de piedra parda de cantería del ynga») y techadas con paja a doble agua que recuerdan el galpón «con una entrada a la culata» descrito por Pedro Pizarro en el Cuzco (Pizarro, 1986 [1571]: 160) 
Al estudiar cómo el estilo y el estatuto podían verse reflejados arquitectónicamente, Susan Niles señaló ya hace algunos años la necesidad de prestar atención a la terminología empleada en las fuentes etnohistóricas para referirse a las estructuras arquitectónicas indígenas, ya que podría brindarnos información sobre las actividades realizadas en ellas. En este sentido, resulta muy sugerente que en la documentación colonial, el complejo palaciego de Huayna Cápac sea descrito como «unos tambos» (Niles, 1993: 168) pues, como veremos a continuación, fuentes coetáneas respaldan la posibilidad de que el nombre indígena utilizado para referirse a las alargadas salas techadas incaicas haya sido tambo y no kallanka.

El primer cronista en darnos alguna pista sobre la estrecha relación existente entre los galpones incaicos y el término tambo fue Pedro Cieza de León, quien al describir los «tambos o palacios reales» de los incas resalta sus extensas longitudes:

«... y a los chancas mandó que se hiziese una casa larga a manera de tanbo...» (Cieza de León, 1996a [1550]: 135).

«En lo más principal de la prouincia (de Guamachuco) está vn campo grande: donde estavan edificados los tambos o palacios reales: entre los quales ay dos de anchor de veynte y dos pies, y de largor tienen tanto como vna carrera de cauallo...» (Cieza de León, 1996b [1550]: 236)

«Delante de ella (provincia de Conchucos) cantidad de diez y seys leguas está la prouincia de Piscobamba: en la qual auía un tambo o aposento para los señores de piedra algo ancho y muy largo» (Cieza de León, 1996b [1550]: 239).

La asociación galpón-tambo se hace explicita en el testimonio del jesuita Bernabé Cobo, cuando describe a los tambos incaicos con las siguientes palabras:

«En lo que toca a su traza y forma, eran unas grandes casas o galpones de sola una pieza, larga de ciento hasta trescientos pies, y ancha treinta a lo menos y a lo más cincuenta, toda descombrada y escueta, sin división de aposentos, ni apartamientos, y con dos o tres puertas, todas en la una acera iguales trechos. Muchos de los tambos antiguos duran enteros y sirven todavía; y de los que se han caído, que son los más, se ven los rastros y ruinas; de los que están en pie son los mejores, más capaces y bien tratados que yo he visto el de Vilcas y el del pueblo de Moho...»(Cobo, 1964 [1653]: 240).

El significado primigenio del término tambo, por consiguiente, podría haber sido el de gran sala techada, un tipo de estructura que fue identificada por los cronistas españoles como el «palacio» del Inca. Sin embargo, tanto las evidencias arqueológicas como las fuentes etnohistóricas señalan también que en la sociedad incaica las unidades residenciales básicas (incluidas las de los gobernantes cusqueños) fueron los grupos kancha o conjunto de estructuras cuadrangulares cercadas por un patio interno (Gasparini \& Margolies, 1977: 186-193), las cuales solamente en algunas ocasiones se encuentran asociadas a grandes galpones. $\mathrm{Si}$ las residencias de los gobernantes cusqueños estuvieron constituidas por grupos kancha, ¿cómo explicar la correspondencia palacio inca/galpón presente en varias fuentes documentales de los siglos XVI y XVII?

$\mathrm{Al}$ respecto, consideramos que la existencia de galpones al interior de los complejos palaciegos incaicos 3 , junto con el limitado repertorio de categorías arquitectónicas amerindias utilizadas comparativamente por los cronistas españoles para referirse a las manifestaciones arquitectónicas andinas, habrían contribuido a consolidar la asociación palacio inca/galpón. La segunda de las explicaciones sugerida se encuentra íntimamente ligada al origen y significado que tuvo el término galpón durante los siglos XVI y XVII.

Sabemos que la voz galpón no pertenece a ninguna de las lenguas indígenas habladas en el territorio andino en tiempos prehispánicos. Fue introducida por los españoles durante los primeros años de la Conquista, apareciendo registrada ya en 1534 durante la fundación de la ciudad del Cuzco (Rowe, 1990: 102-103).

Pese a que el Inca Garcilaso atribuyó el origen del término galpón a las islas de Barlovento (Garcilaso, 2005 [1609]: vol. I, 6), desde hace más de una década, la Real Academia Española de la Lengua sugiere su vinculación etimológica con la voz náhuatl calpúlli, traducida como «casa grande» (Real Academia Española de la Lengua, 1992: 716). El origen del término galpón, por consiguiente, se encontraría en el dialecto náhuatl pipil, perteneciente a la familia Uto-Azteca, que se hablaba en territorio nicaragüense en tiempos prehispánicos (Tous, 1999: 62).

Según lo señalara Fernández de Oviedo en el siglo XVI, la palabra galpón podía tener dos acepciones en territorio nicaragüense: se refería a los caciques menores que dependían de otro principal (teyte) y a las construcciones más importantes de os pueblos indígenas en las que se reunía el cabildo o Consejo del Monexico ${ }^{4}$.

«En algunas partes hay señores ó principales de mucho estado ó gente assimesmo el cacique de Teocatega y el de Mistega, y el de Nicaragua y el de Nicoya é otros tienen vassallos principales é cavalleros (digo varones, que son cabeceras de provincias o pueblos con señoria por sí con vasallos), á los quales llaman galpones: é aquellos acompañan é guardan la persona del principe ordinariamente é son sus cortesanos é principales..

[Los miembros del Consejo del Monexico se reunían en] «casas de cabildo» que... llaman galpón, pero según yo ví muchos portales en las plaças de aquella tierra, é aquellos, aunque juntos, es para tener sus divisiones, é son apartados cada uno para sí, en los cuales en cada uno hay un principa con çierto número de gente, que siempre están allí en guarda del señor prinçipal, é cada portal de aquellos llaman galpon.

3 En el caso del palacio Amarucancha, por ejemplo, durante la repartición de solares y terrenos efectuada en el Cuzco el 29 de octubre de 1534, dos de sus solares fueron entregados al teniente de gobernador Hernando de Soto, mientras que un galpón grande del mismo fue reservado para que funcionara alli la Casa de Cabildo (Rowe, 1990: 102-103).

4 En algunas ocasiones, Fernández de Oviedo (1976 [1535]: 464) utiliza otro término nicaragüense para referirse a los galpones en que vivían los guardas del cacique principal: buhío. Este uso indistinto de galpón y buhío también estará presente en los Andes cuando, por ejemplo, algunos cronistas hagan referencia al denominado «Cuarto del rescate» de Atahualpa en Cajamarca. 
Y en aquellos portales que están á trechos cubiertos en torno a la plaça el qual portal se llama galpon, allí duermen los mançebos que no tienen mugeres, é porque estén allí puestos é juntos para la guerra; é haçen su vela ordenada cada noche, porque los contrarios enemigos no salten de noche» (Fernández de Oviedo, 1976 [1535]: 306-307, 343-346).

Consideramos que este modelo nicaragüense, en el que las viviendas de los caciques secundarios y de la gente de guerra (galpones) se distribuían rodeando la plaza principal y adoptaban la forma de largas salas techadas, fue el que llevó a que varios cronistas identificaran a las estructuras alargadas incas (tambos) como palacios. Basta con observar el plano de uno de estos pueblos indígenas de Nicaragua, el asentamiento de Teocatega, presentado por el cronista Fernández de Oviedo (1976 (1535): 461), para verificar la gran similitud existente entre las plantas de estas construcciones y las de los edificios incaicos.

\section{COMENTARIOS FINALES}

La investigación realizada ha evidenciado la necesidad de llevar a cabo una exhaustiva revisión de la terminología quechua empleada por los arqueólogos andinistas para designar las diversas manifestaciones materiales incaicas, con el objetivo de evitar la creación de categorías tipológicas ficticias y las interpretaciones funcionales imprecisas originadas tras la confrontación de los datos arqueológicos con la información etnohistórica. En este sentido, la consulta de fuentes escritas coloniales debería implicar el manejo de ciertas categorías clasificatorias empleadas por los cronistas o amanuenses, las cuales facilitarían el entendimiento de lo que el redactor buscaba describirnos.

A lo largo del presente trabajo, a partir de una revisión de fuentes lingüísticas, etnohistóricas y arqueológicas, hemos intentado reconocer el significado original de una categoría ampliamente utilizada en el ambiente académico: la kallanka. La revisión de las escasas fuentes etnohistóricas conocidas en las que se registra este vocablo nos lleva al convencimiento del uso impreciso que se viene dando al término, tomando en consideración que éste muy probablemente servía para referirse a espacios abiertos (patios o corrales) de carácter ceremonial y no a largas salas techadas o galpones. Estos últimos, según lo sugieren las fuentes documentales coloniales, habrían recibido el nombre indígena de tambo.

Asimismo, en un intento por explicar la asociación existente al interior de las crónicas andinas de los siglos XVI y XVII entre los galpones y los palacios incaicos, hemos recurrido a la revisión de la situación registrada en territorio nicaragüense durante la primera mitad del siglo $\mathrm{XVI}$, debido fundamentalmente a que en esta región estuvo presente una correspondencia similar que pudo haber influenciado la percepción que los primeros conquistadores y cronistas se formaron sobre la arquitectura incaica. Desde nuestro punto de vista, el hecho que las residencias reales incaicas estuvieran conformadas por «complejos palaciegos» en los que grupos kancha y tambos (galpones) se encontraban físicamente relacionados compartiendo espacios, y la existencia de manifestaciones arquitectónicas análogas en Mesoamérica, contribuyeron a la consolidación de una percepción hispana en la que una forma arquitectónica incaica (sala techada) fue asociada a una funcionalidad preferencial (servir como palacio).

\section{Referencias citadas}

ACADEMIA MAYOR DE LA LENGUA QUECHUA, 1995 - Diccionario quechua-españolquechua, 928 pp.; Cuzco: Municipalidad del Cuzco.

AGURTO CALVO, S., 1987 - Estudios acerca de la construcción, arquitectura y planeamiento incas, 295 pp.; Lima: Cámara Peruana de la Construcción.

BECKER ÁLVAREZ, C., 1995 - Reconstruyendo las pautas del manejo de la llama: Los basurales del Pukara de Turi. In: Informe del Proyecto «Fases Culturales del Pukara de Turi: El Inka y sus predecesores». FONDECYT n. 1940096 < http://www.geocities. com/cristianbecker/informes/Turi_1995.pdf $>$.

BERTONIO, L., 1984 [1612] - Vocabulario de la lengua aymara, 473 pp.; Cochabamba: CERES, IFEA, MUSEF

BOUCHARD, J.-F., 1983 - Contribution à l'étude de l'architecture Inca. Établissements de la vallée du Río Vilcanota-Urubamba, 119 pp.; París: Éditions Maison des Sciences de L'Homme, Cahiers d'Archéologie et d'Ethnologie d'Amérique du Sud.

CABALLERO, G. B. de, 1980 - Incarracay. El palacio de Huayna Capac, 5 pp.; Cochabamba: Universidad Mayor de San Simón, Instituto de Investigaciones Antropológicas, Museo Arqueológico.

CALANCHA, A. de la, 1974-1981 [1638] - Crónica Moralizada, 6 vols.; Lima: UNMSM. Edición de lgnacio Prado Pastor.

CARRANZA ROMERO, F., 2003 - Diccionario Quechua ancashino-castellano, 293 pp.; Madrid: Iberoamericana; Frankfurt am Main: Vervuert Verlag.

CIEZA DE LEÓN, P. de, 1996a [1550] - Crónica del Perú. Primera parte, 354 pp.; Lima: Fondo Editorial PUCP, Academia Nacional de la Historia.

CIEZA DE LEÓN, P. de, 1996b [1550] - Crónica del Perú. Segunda parte, 238 pp.; Lima: Fondo Editorial PUCP, Academia Nacional de la Historia.

COBO, B., 1964 [1653] - Historia del Nuevo Mundo, 2 vols. In: Obras del P. Bernabé Cobo de la Compañía de Jesús (F. Mateos, ed.); Madrid: Ediciones Atlas. Biblioteca de Autores Españoles.

DUVIOLS, P., 2003 - Procesos y visitas de idolatrías. Cajatambo, siglo XVII, 882 pp.; Lima: Fondo Editorial PUCP, Instituto Francés de Estudios Andinos.

FARRINGTON, I. \& ZAPATA, J., 2003 - Nuevos cánones de arquitectura inka: investigaciones en el sitio de Tambokancha (Tumibamba, Jaquijahuana, Cuzco). Boletín de Arqueología PUCP, 7: 57-77; Lima.

FERNÁNDEZ DE OVIEDO, G., 1976 [1535] - Historia General y Natural de las Indias, Islas y Tierra Firme del Mar Océano. In: Nicaragua en los Cronistas de Indias: Oviedo (E. Pérez Valle, ed.); Managua: Banco de América. Colección Cultural del Banco de 
América, Serie Cronistas n. ${ }^{\circ} 3$.

GARCILASO DE LA VEGA, I., 2005 [1609] - Comentarios Reales de los Incas, 2 vols., 880 pp.; Lima: Fondo de Cultura Económica. Edición de Carlos Araníbar.

GASPARINI, G. \& MARGOLIES, L., 1977 - Arquitectura Inka, 347 pp.; Caracas: Centro de Investigaciones Históricas y Estéticas, Facultad de Arquitectura y Urbanismo. Universidad Central de Venezuela.

GONZÁLEZ HOLGUín, D., 1989 [1608] - Vocabulario de la lengua general de todo el Peru llamada Quechua o del Inca, 707 pp.; Lima: Universidad Nacional Mayor de San Marcos.

HYSLOP, J., 1990 - Inka settlement planning, 377 pp.; Austin: University of Texas.

LARA, J., 1978 - Diccionario qhëshwa-castellano, castellano-qhëshwa, 422 pp.; La Paz/ Cochabamba: Los Amigos del Libro.

MALPASS, M. A., 1993 - Provincial Inca Archaeology and Ethnohistory: An Introduction. In: Provincial Inca: Archaeological and Ethnohistorical Assesmant of the Impact of the Inca State (M. A. Malpass, ed.): 1-13; lowa: University of lowa.

MATOS, R., 1994 - Pumpu: centro administrativo inka de la Puna de Junín, 327 pp.; Lima: Editorial Horizonte, Fondo Editorial del BCRP, TARAXACUM.

MEINKEN, A. K., 2000-2001 - Trabajos arqueológicos efectuados en edificios largos tipo kallanka: Maucallacta, Tompullo 2, Achaymarca. Informe Preliminar, Campaña 1999. Andes. Boletín de la Misión Arqueológica Andina, 3: 127-181; Varsovia.

MEINKEN, A. K., 2005a - Sobre el problema de definición de los edificios incaicos llamados kallanka. Sequilao. Revista de Historia, Arte y Sociedad, 15: 57-65; Lima.

MEINKEN, A. K., 2005b - Trabajos arqueológicos en las kallankas de los sitios Ccopan, La Joya y Achaymarca, Temporada 2004. Andes. Boletín de la Misión Arqueológica Andina, 6: 65-92; Varsovia. Proyecto Arqueológico Condesuyos. Volumen III (Ziółkowski, M. S., Belan Franco, L. A. \& Sobczyk, M., eds.).

MORRIS, C., 1966 - El Tampu Real de Tunsucancha. Cuadernos de Investigación, 1: 95107; Huánuco: Facultad de Letras y Educación de la Universidad Nacional Hermilio Valdizán.

MORRIS, C., 1972 - The identification of function in Inca architecture and ceramics. Actas y Memorias del XXXIX Congreso Internacional de Americanistas, vol. III: 135-144; Lima: Compañía de impresiones y Publicidad S.A.

MORRIS, C., 1999 - La arquitectura del Tahuantinsuyo. In: Los Incas: Arte y símbolos (F. Pease, ed.): 1-59; Lima: Banco de Crédito del Perú. Colección Familiar Arte y Tesoros del Perú.

MORRIS, C. \& THOMPSON, D. E., 1985 - Huanuco Pampa: an Inca city and its hinterland, 181 pp.; New York: Thames and Hudson Ltd.

MUÑOZ, M. de los Á., 2007 - The Kallanka at Samaipata, Bolivia: an example of Inka monumental architecture. In: Variations in the expression of Inka power (R. Burger, C. Morris \& R. Matos Mendieta, eds.): 255-265; Washington D.C.: Dumbarton Oaks Research Library and Collection, Harvard University Press. Symposium at Dumbarton Oaks, 18 and 19 October 1997

MURÚA, M. de, 2004 [1590] - Historia del origen, y genealogía real de los Reyes Ingas del Piru, de sus hechos, costumbres, trajes y manera de gobierno, 150 pp. Madrid: Testimonio: Sociedad Estatal para la Acción Cultural Exterior Edición Facsimilar.

NILES, S. A., 1993 - The provinces in the heartland: Stylistic variation and architectural innovation near Inca Cuzco. In: Provincial Inca: Archaeological and Ethnohistorical Assesmant of the Impact of the Inca State (M. A. Malpass, ed.): 145-176; lowa:
University of lowa.

PARDO, L. A., 1957 - Historia y arqueología del Cuzco, vol. I; Callao: Imprenta del Colegio Militar Leoncio Prado.

PÉREZ, I. VIVANCO, C. \& AMORÍN J J., 2003 - Sondor, establecimiento inca en Pacucha Andahuaylas. Boletín de Arqueología PUCP, 7: 365-385; Lima.

PIZARRO, P., 1986 [1571] - Relación del Descubrimiento y Conquista de los Reinos del Perú, 277 pp.; Lima: Fondo Editoral PUCP. Edición de Guillermo Lohmann Villena.

POLO DE ONDEGARDO, J., 1916 [1571] - Relación de los fundamentos acerca del notable daño que resulta de no guardar a los indios sus fueros. In: Informaciones acerca de la religión y gobierno de los incas por el Licenciado Polo de Ondegardo $(\mathrm{H}$. Urteaga \& C. Romero, eds.): 45-188; Lima: Sanmarti. Colección de libros y documentos \& C. Romero, eds.): 45-188; Lima. Sant referentes a la Historia del Perú, vol. III.

PROTZEN, J. P., 1993 - Inca architecture and construction at Ollantaytambo, 303 pp.; New York: Oxford University Press.

RAFFINO, R., ITURRIZA, R. \& GOBBO, J. D., 2000 - Revalorización de la Kallanka 1 de El Shincal de Quimivíl. Relaciones de la Sociedad Argentina de Antropología, XXV: 313-344; Buenos Aires.

REAL ACADEMIA ESPAÑOLA DE LA LENCUA, 1992 - Diccionario de la Lengua Española; Madrid: Espasa Calpe. 21a Edición.

ROWE, J., 1981 - Una relación de los adoratorios del antiguo Cuzco. Histórica, 5 (2): 209-261; Lima.

ROWE, J., 1990 - Los monumentos perdidos de la plaza mayor del Cuzco incaico. Saqsaywaman, 3: 81-109; Cuzco.

SAMANÉZ ARGUMEDO, R. \& ZAPATA RODRÍGUEZ, J., 1999 - El centro ceremonial inka de Choquequirao. Arkinka, 46: 80-94; Lima.

SAMANÉZ ARGUMEDO, R. \& ZAPATA RODRÍGUEZ, J., 2001 - Machupitumarca: umbral de los glaciares del Ausangate. Arkinka, 66: 92-101; Lima

SILLAR, B. \& DEAN, E., 2002 - Identidad étnica bajo el dominio inka: una evaluación arqueológica y etnohistórica de las repercusiones del estado inka en el grupo étnico Canas. Boletín de Arqueología PUCP, 6: 205-264; Lima.

TAYLOR, G., 1999 - Ritos y tradiciones de Huarochirí, 502 pp.; Lima: Instituto Francés de Estudios Andinos, Banco Central de Reserva del Perú, Universidad Particular Ricardo Palma

TOUS MATA, M., 1999 - Cambio y continuidad de las estructuras de poder precolombinas en la provincia de Nicaragua durante el siglo XVI. In: Estrategias de poder en América Latina: VII Encuentro-Debate América Latina ayer y hoy (P. García Jordán, ed): 61-78; Barcelona: Edicions Universitat Barcelona.

VEGA, A. de la, 1948 [1600] - Historia del Colegio y Universidad de San Ignacio de Loyola de la Ciudad del Cuzco, 219 pp.; Lima: Compañía de Impresiones y Publicidad Enrique Bustamante y Ballivián, sucesor. Biblioteca Histórica Peruana, tomo VI.

ZECENARRO BENAVENTE, G., 2000 - Q'aqyaqhawana. Arkinka, 60: 88-100; Lima. 
Pedidos: IFEA, Casilla 18-1217, Lima 18 - Perú, Tel. 4476070 Fax: 4457650 -E-mail: postmaster@ifea.org.pe Web: http://www.ifeanet.org

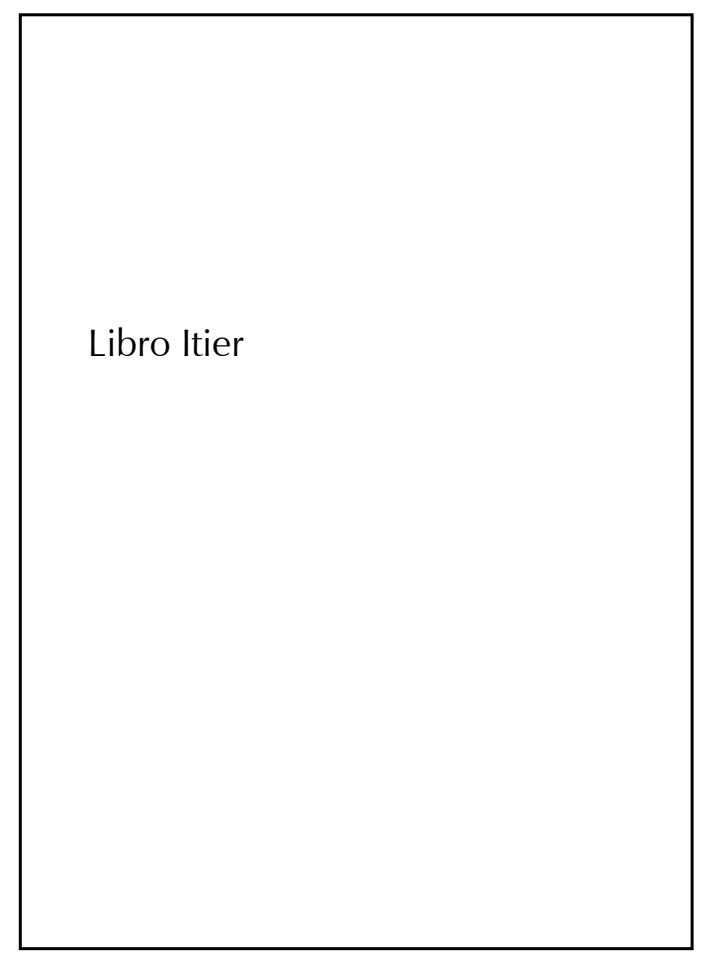

Coedición: Institut français d'Études andines (IFEA, UMIFRE 17, CNRS-MAEE) - FLACSO Ecuador

Coedición: Institut français d'Études andines (IFEA, UMIFRE 17, CNRS-MAEE) Instituto Riva-Agüero, Pontificia Universiddad Católica del Perú
Libro Gros-Foyer 